\title{
降雨强度和时间频次对内蒙古典型草原土壤氮矿 化的影响
}

朱志成 ${ }^{1,2}$ 黄 银 ${ }^{1,2}$ 许丰伟 1,2 邢 稳 1,2 郑淑霞 $1^{*}$ 白永飞 1

${ }^{1}$ 中国科学院植物研究所植被与环境变化国家重点实验室, 北京 $100093{ }^{2}{ }^{2}$ 中国科学院大学, 北京 100049

摘 要 为了深入地理解和认识全球变化背景下草原生态系统土壤氮矿化的变化动态及其对气候变化的响应机制, 以内蒙 古典型草原不同围封年限样地(1999年围封和2013年围封)为研究对象, 通过改变降雨量(增加降雨50\%和减少降雨50\%)和降 雨时间频次(连续3年降雨处理; 连续2年降雨处理, 然后自然恢复1年; 降雨1年处理, 然后自然恢复1年), 共设置7个降雨处 理, 研究不同降雨强度和时间频次对内蒙古典型草原土壤氮矿化的影响及其调控因子。研究结果表明: 1)随着减雨或增雨时 间频次的增加(由1年减雨或增雨至连续3年减雨或增雨处理), 土壤净氮矿化速率和净硝化速率会降低, 且土壤净氮矿化速率 和净硝化速率的最大值发生在增雨或减雨1年恢复1年处理中, 表明较高的降雨强度和时间频次对土壤净氮矿化速率和净硝 化速率会产生抑制作用, 而适宜的土壤水分和温度条件更有利于土壤氮矿化作用。2)与2013年围封样地相比, 1999年围封样 地的土壤净氮矿化速率和净硝化速率、土壤累积氮矿化量和硝化量更高, 表明长期的自然封育有利于养分储存和土壤质量恢 复。3)长期的连续性增雨或减雨处理会显著影响土壤含水量和土壤温度(短期的间断性增雨或减雨处理则无显著影响), 但二 者对土壤氮矿化的影响在两块样地的表现不同, 如在2013年围封样地, 土壤无机氮和净氮矿化速率主要受土壤水分的影响, 而在1999年围封样地, 土壤无机氮和净氮矿化速率主要受土壤温度的影响, 土壤水分甚至对净氮矿化速率产生了明显的负效 应。研究表明, 降雨强度和时间频次对内蒙古典型草原土壤氮矿化具有重要影响, 但影响大小因样地而异, 与土壤质地、群 落组成和干扰程度等因素有关。

关键词 降雨强度; 降雨时间频次; 土壤氮矿化; 土壤含水量; 土壤温度; 羊草草原; 围封样地

引用格式: 朱志成, 黄银, 许丰伟, 邢稳, 郑淑霞, 白永飞 (2017). 降雨强度和时间频次对内蒙古典型草原土壤氮矿化的影响. 植物生态学报, 41, 938-952. doi: 10.17521/cjpe.2017.0056

\section{Effects of precipitation intensity and temporal pattern on soil nitrogen mineralization in a typical steppe of Nei Mongol grassland}

ZHU Zhi-Cheng ${ }^{1,2}$, HUANG Yin ${ }^{1,2}$, XU Feng-Wei ${ }^{1,2}$, XING Wen $^{1,2}$, ZHENG Shu-Xia $^{1 *}$, and BAI Yong-Fei ${ }^{1}$

${ }^{1}$ State Key Laboratory of Vegetation and Environmental Change, Institute of Botany, the Chinese Academy of Sciences, Beijing 100093, China; and ${ }^{2}$ University of Chinese Academy of Sciences, Beijing 100049, China

\section{Abstract}

Aims Our objective is to: 1) explore the dynamics of soil nitrogen (N) mineralization in a grassland ecosystem in response to the changes in precipitation intensity and temporal distribution, and 2) identify the controlling factors.

Methods The two study sites located in a typical steppe of the Nei Mongol grassland were fenced in 2013 and 1999, respectively. Our field experiment includes manipulations of three levels of precipitation intensity (increased 50\%, decreased 50\%, control) in three temporal patterns (increased or decreased precipitation for three years; increased or decreased precipitation for two years and no manipulation for one year; increased or decreased precipitation for one year and no manipulation for one year).

Important findings 1) The soil net $\mathrm{N}$ mineralization and net nitrification rates decreased with changes in the temporal distributions of precipitation from one year to three years, with the maximum values of soil net $\mathrm{N}$ mineralization and nitrification rates observed in the treatments of increased or decreased precipitation for one year and no manipulation for one year (+PY1 or -PY1). This indicates that the high precipitation intensity and longer precipitation may have negative effects on soil net $\mathrm{N}$ mineralization and nitrification rates, while the

收稿日期Received: 2017-03-09 接受日期Accepted: 2017-06-01

* 通信作者Author for correspondence (E-mail: zsx@ibcas.ac.cn) 
moderate soilmoisture and temperature may stimulate soil mineralization. 2) The soil net $\mathrm{N}$ mineralization and nitrification rates, soil cumulative $\mathrm{N}$ mineralization, and nitrification in the fenced site in 1999 were higher than those in the site fenced in 2013, implying that a long-term enclosure may have promoted nutrient storage and soil quality restoration. 3) The long-term treatments of increased or decreased precipitation had significant effects on soil water content and temperature, whereas the short-term, discontinuous precipitation produced minor effects on soil moisture and temperature. Moreover, the controlling factors for soil $\mathrm{N}$ mineralization were different between the two fields. Soil moisture had a major effect on soil inorganic $\mathrm{N}$ content and net $\mathrm{N}$ mineralization rate in the site fenced in 2013, while soil temperature played a dominant role in the site fenced in 1999, with the net $\mathrm{N}$ mineralization rate depressed by higher soil moisture. Our findings suggest that the precipitation intensity and temporal distribution had important impacts on soil $\mathrm{N}$ mineralization in the Inner Mongolia grassland; these effects was site-dependent and particularly related to soil texture, community composition, and disturbance, and other factors.

Key words precipitation intensity; precipitation temporal distribution; soil N mineralization; soil water content; soil temperature; Leymus chinensis steppe; fenced site

Citation: Zhu ZC, Huang Y, Xu FW, Xing W, Zheng SX, Bai YF (2017). Effects of precipitation intensity and temporal pattern on soil nitrogen mineralization in a typical steppe of Nei Mongol grassland. Chinese Journal of Plant Ecology, 41, 938-952. doi: 10.17521/cjpe.2017.0056

IPCC (2014)指出: 随着全球气候的变化, 全球 性极端气候事件发生的频率会逐渐增加, 其中降雨 格局的不断改变, 尤其是降雨强度的变化会对土壤 氮矿化过程产生重要影响(Hu et al., 2014)。研究表 明, 降雨影响土壤氮矿化过程, 主要是通过影响土 壤含水量、土壤温度和氮的淋溶, 进而影响土壤氮 循环过程, 特别是降雨量的增大会使得土壤含水量 显著提高, 土壤温度下降, 从而影响土壤微生物的 活性, 最终对土壤氮矿化甚至对整个生态系统的氮 循环产生较大的影响(同小娟等, 2005; Cregger et al., 2014; Liao et al., 2016)。

土壤氮矿化主要是指土壤中的有机氮经过微生 物的分解作用转化为无机氮 (主要为 $\mathrm{NH}_{4}^{+}-\mathrm{N}$ 和 $\mathrm{NO}_{3}^{-}-\mathrm{N}$ )的过程(Chapin et al., 2011), 这也是植物利 用土壤中无机氮合成自身体内许多重要物质的主要 途径(Jackson et al., 2008)。尽管土壤氮矿化为植物 和微生物的生长提供了非常重要的物质基础, 但是 它又易受到水分条件的影响(Burke et al., 1998), 如 在受水分限制的生态系统中, 土壤中氮元素的吸收 主要受限于水分的可利用性。在降雨量和土壤含水 量增加的情况下, 土壤中的无机氮会随之增加, 促 进植物对无机氮的吸收, 但这也会导致土壤中可利 用性氮的减少(唐树梅和漆智平, 1997; Chen et al., 2012)。同理, 当土壤含水量降低时, 由于水分的限 制作用抑制了植物对土壤中可利用性氮的吸收, 从 而有利于土壤无机氮的累积(Weltzin et al., 2009)。也 有一些研究表明, 当土壤含水量超过某个临界值时,
会抑制土壤氮矿化过程(吴建国等, 2007; 李玉霖等, 2013)。尽管对土壤氮矿化的研究已有很多, 但是并 没有得出较一致的结论。如早期的研究发现, 从干 旱草原到湿地生态系统, 土壤氮矿化作用会随着土 壤水分的增加而增强(Tracy \& Frank, 1998), 然而也 有一些研究发现, 土壤氮矿化作用会随着土壤水分 的不断增加而逐渐下降(Aranibar et al., 2004)。近期 武丹丹等(2016)通过降雨试验发现, 降雨量的改变 显著地影响了土壤氮矿化过程, 且土壤 $\mathrm{NH}_{4}^{+}-\mathrm{N}$ 和 $\mathrm{NO}_{3}^{-}-\mathrm{N}$ 的含量随着土壤水分的增加而逐渐增加。此 外, 土壤氮矿化作用也会受到土地利用方式的影响, 使其呈现出相反的变化(Templer et al., 2005), 如 Frank等(2000)发现在黄石公园不同的草地生态系统 中, 与围封样地相比, 放牧样地的土壤净氮矿化速 率较高。Andersson等(2002)发现随着施肥梯度的增 加, 土壤净氮矿化速率也在不断增加, 而在非施肥 样地呈现出下降的趋势。然而, Goodale和Aber (2001) 发现不同的土地利用历史(如火烧、农田和风蚀等) 并没有对土壤氮矿化产生显著的影响。整体而言, 对土壤氮矿化的研究主要是集中于不同的降雨强度 梯度的调查研究, 或是在既定的区域范围内进行控 制试验研究(Amundson et al., 2003), 但这些研究并 没有清晰地说明在不同的降雨处理和土地利用历史 条件下, 影响土壤氮矿化的主要调控因子是什么。 因此, 本研究在充分了解已有的关于降雨影响土壤 氮矿化的研究进展的基础上, 结合全球降雨变化的 年际间间断性特点(Knapp et al., 2001), 设计了不同 
的降雨强度和时间频次对土壤氮矿化影响的研究方 案和思路。

在我国，草地生态系统约占国土总面积的 41.7\%, 草地面积居世界第二位(中华人民共和国农 业部畜牧兽医司和全国畜牧兽医总站, 1996)。研究 表明, 内蒙古温带典型草原是对全球变化最为敏感 的区域之一(尹燕亭等, 2011), 其中又以锡林郭勒半 干旱草原最具代表性(姜恕等, 1988)。与其他生态系 统(如森林、农田等)相比, 干旱半干旱草原生态系统 对降水的变化更为敏感(Knapp \& Smith, 2001)。因此, 本研究在内蒙古典型草原, 选择不同围封年限样地 (1999年围封和2013年围封), 通过设置降雨控制试 验, 研究不同降雨强度和时间频次对土壤氮矿化过 程的影响及其调控因子, 拟回答以下两个方面的科 学问题: 1)降雨强度和时间频次的改变是如何影响 土壤氮矿化过程的? 其影响机制是什么? 2)降雨强 度和时间频次的改变对2013年围封样地(退化严重) 和1999年围封样地(恢复较好)土壤氮矿化的影响有 何不同? 如果这两块样地对降雨变化的响应具有明 显的差异性, 其原因是什么? 本研究针对以上科学 问题进行深入的试验探究, 以期为揭示全球变化背 景下, 干旱半干旱草原生态系统土壤氮矿化对降雨 格局变化的响应及适应机制提供理论依据。

\section{1 材料和方法}

\section{1 研究地概况}

试验样地位于内蒙古锡林郭勒草原中国科学院 内蒙古草原态系统定位研究站的羊草群落样地 (43.55 $\mathrm{N}, 116.67^{\circ} \mathrm{E}$, 海拔1 200-1 $\left.250 \mathrm{~m}\right)$ 。植被类 型属于温带典型草原, 气候类型为半干旱季风气候。 该地区多年平均年降水量(1970-2015年)为336 mm, 且 $60 \%-80 \%$ 降水集中于 5-8月份, 多年平均气温 (1970-2015年)为 $0.5{ }^{\circ} \mathrm{C}$ 。土壤类型为暗栗钙土, 土层 深度可达1 m (Bai et al., 2004)。1999年围封样地自 1999年开始围封, 至今已经有18年的禁牧历史, 植 物群落自然恢复较好, 主要优势物种为羊草 (Leymus chinensis)、大针茅(Stipa grandis)和羽茅 (Achnatherum sibiricum)等; 2013年围封样地自2013 年开始围封, 草地重度退化, 主要优势物种为大针 茅、糙隐子草(Cleistogenes squarrosa)、羊草和冰草 (Agropyron cristarum) 等。两块样地相距约 $200 \mathrm{~m}$, 样 地面积均为 $60 \mathrm{~m} \times 100 \mathrm{~m}$, 每个增雨或减雨试验小
区面积为 $3.6 \mathrm{~m} \times 3.6 \mathrm{~m}$, 且试验小区间距为 $1 \mathrm{~m}$ 。

\section{2 试验设计}

本试验采用随机区组设计, 包括降雨强度和降 雨时间频次 2 个处理, 每个处理分别设置 3 个水平, 其中降雨强度的 3 个水平为: 增雨 $50 \%(+\mathrm{P})$ 、减雨 $50 \%(-\mathrm{P})$ 、对照 $(\mathrm{CK})$ 。降雨时间频次的 3 个水平为: 连续3年增雨或减雨处理 $(\mathrm{Y} 3)$ 、连续2年增雨或减雨 处理, 然后自然恢复1年(Y2)、增雨或减雨1年处理, 然后自然恢复1年(Y1), 共设计7个处理, 沿降雨梯 度分别为: $-P Y 3 、-P Y 2 、-P Y 1$ 、对照 $(C K) 、+P Y 1$ 、 $+P Y 2 、+P Y 3$, 每个处理 5 个重复。增雨和减雨试验 装置参照Yahdjian和Sala (2002)的降雨试验平台, 整 个装置采用不锈钢管架搭建而成(面积 $3.61 \mathrm{~m} \times$ $3.63 \mathrm{~m}$, 上端高 $1.5 \mathrm{~m}$, 下端高 $1.0 \mathrm{~m}$ ), 然后将 PVC 板(透光性大于 $95 \%$ )对折 90 度, 固定在减雨棚上, 并 使其水平面积正好等于遮雨棚的 $1 / 2$, 以保证减少 降雨 $50 \%$ 。在每一个减雨装置末端, 放置两个固定 的橡胶桶(用连通管连接), 以接收减少 $50 \%$ 的自然 降雨, 且在每次自然降雨过后, 选择在早晨或者傍 晚时间，将从减雨 $50 \%$ 小区收集到的自然降水，通 过喷壶均匀地喷酒到增雨 $50 \%$ 的小区, 以确保增雨 达到 $50 \%$ 。这样既可以避免中午较强的蒸发作用的 影响, 又可确保没有地表径流发生, 对照不做任何 处理。该试验自2013年5月底开始进行降雨处理，并 于6月初进行植物和土壤指标的各项观测, 土壤氮 矿化试验于2015年6月初到9月初进行。

\section{3 土壤氮矿化培养试验}

土壤氮矿化培养试验从2015年6月初开始，到 2015年9月初结束, 采用树脂芯法, 每隔30天采集一 次土壤样品。具体方法为: 6月初, 在每个小区内, 垂直砸入 2 个PVC管(内径 $5.2 \mathrm{~cm}$, 高 $10 \mathrm{~cm}$ ), 其中一 个用聚乙烯膜封口，进行原位培养试验，另外一个 取出, 进行土壤理化性质测定。每隔30天, 取出培养 好的PVC管, 同时再砸入另外一个PVC管, 并用聚 乙烯膜封口和原位培养, 至9月初, 共采集4次土壤 样品。将每次采集的土壤样品, 先进行过篮(直径 $2 \mathrm{~mm}$ )处理, 然后称取 $10 \mathrm{~g}$ 鲜土, 放入 $100 \mathrm{~mL}$ 的塑 料瓶中, 加入 $50 \mathrm{~mL} 2 \mathrm{~mol} \cdot \mathrm{L}^{-1}$ 的 $\mathrm{KCl}$ 溶液, 放于振荡 器(高速)中振荡 $1 \mathrm{~h}$, 然后用直径 $9 \mathrm{~cm}$ 的滤纸过滤并 提取上清液, 最后利用全自动流动分析仪(Kjektec System 1026 Distilling Unit, Hoganas, Sweden)进行 $\mathrm{NH}_{4}^{+}-\mathrm{N}$ 和 $\mathrm{NO}_{3}^{-}-\mathrm{N}$ 的测定。 


\section{4 土壤净氮矿化速率和净硝化速率计算}

土壤净氮矿化速率和净硝化速率的计算方法参 照Shan等(2011), 计算公式如下:

$$
\begin{aligned}
& A_{\mathrm{amm}}\left(\mathrm{g} \cdot \mathrm{m}^{-2}\right)=c\left[\mathrm{NH}_{4}^{+}-\mathrm{N}\right]_{i+1}-c\left[\mathrm{NH}_{4}^{+}-\mathrm{N}\right]_{i} \\
& A_{\text {nit }}\left(\mathrm{g} \cdot \mathrm{m}^{-2}\right)=c\left[\mathrm{NO}_{3}^{-}-\mathrm{N}\right]_{i+1}-c\left[\mathrm{NO}_{3}^{-}-\mathrm{N}\right]_{i} \\
& A_{\min }\left(\mathrm{g} \cdot \mathrm{m}^{-2}\right)=A_{\mathrm{amm}}+A_{\mathrm{nit}} \\
& R_{\min }\left(\mathrm{mg} \cdot \mathrm{m}^{-2} \cdot \mathrm{d}^{-1}\right)=A_{\min } / \Delta t \\
& R_{\text {nit }}\left(\mathrm{mg} \cdot \mathrm{m}^{-2} \cdot \mathrm{d}^{-1}\right)=A_{\text {nit }} / \Delta t \\
& \Delta t(\mathrm{~d})=t_{i+1}-t_{i}
\end{aligned}
$$

式中, $\Delta t$ 表示培养时间(d), $t_{i}$ 表示培养前的时间(d), $t_{i+1}$ 表示培养后的时间(d); $c\left[\mathrm{NH}_{4}^{+}-\mathrm{N}\right]_{i}$ 和 $c\left[\mathrm{NH}_{4}^{+}-\mathrm{N}\right]_{i+1}$ 分 别表示培养前后 $\mathrm{NH}_{4}^{+}-\mathrm{N}$ 的含量 $\left(\mathrm{g} \cdot \mathrm{m}^{-2}\right) ; c\left[\mathrm{NO}_{3}^{-}-\mathrm{N}\right]_{i}$ 和 $c\left[\mathrm{NO}_{3}^{-}-\mathrm{N}\right]_{i+1}$ 分别表示培养前后 $\mathrm{NO}_{3}^{-}-\mathrm{N}$ 的含量 $\left(\mathrm{g} \cdot \mathrm{m}^{-2}\right)$; $A_{\mathrm{amm}} 、 A_{\mathrm{nit}}$ 和 $A_{\min }$ 分别表示培养前后 $\mathrm{NH}_{4}^{+}-\mathrm{N} 、 \mathrm{NO}_{3}^{-}-\mathrm{N}$ 和总无机氮 $\left(\mathrm{NH}_{4}^{+}-\mathrm{N}\right.$ 与 $\mathrm{NO}_{3}^{-}-\mathrm{N}$ 之和 $)$ 的累积量 $\left(\mathrm{g} \cdot \mathrm{m}^{-2}\right)$; $R_{\min }$ 和 $R_{\mathrm{nit}}$ 分别表示净氮矿化速率和净硝化速率 $\left(\mathrm{mg} \cdot \mathrm{m}^{-2} \cdot \mathrm{d}^{-1}\right)$ 。所有的数据计算以干质量为基础。

土壤累积氮矿化量为生长季6-8月土壤净氮矿 化量的总和 $\left(\mathrm{g} \cdot \mathrm{m}^{-2}\right)$, 土壤累积硝化量为生长季 $6-8$ 月份土壤 $\mathrm{NO}_{3}^{-}-\mathrm{N}$ 之和 $\left(\mathrm{g} \cdot \mathrm{m}^{-2}\right)$ 。

\section{5 土壤温度和含水量测定}

利用DS1921G纽扣式温度记录仪(Maxim Integrated Products, Sunnyvale, USA)和Diviner 2000土 壤水分测定仪(Sentek, Melbourne, Australia)分别测 定距离地面 $10 \mathrm{~cm}$ 处的土壤温度和含水量。纽扣式温 度记录仪每隔 0.5 h 记录一次数据, 可以较精确地反 映土壤温度的变化动态, 土壤含水量于每个月的初 期、中期和末期各观测一次。

\section{6 统计分析}

采用SAS 9.2 (SAS Institute Inc., Cary, USA)和 SPSS 17.0 (SPSS Inc., Chicago, USA)软件进行统计
分析。采用重复测量方差分析降雨处理和采样时间 (月份) 对土壤 $\mathrm{NH}_{4}^{+}-\mathrm{N} 、 \mathrm{NO}_{3}^{-}-\mathrm{N}$ 和总无机氮、土壤温 度和土壤含水量的影响。通过单因素方差分析方法 分析不同降雨量和时间频次处理下 $\mathrm{NH}_{4}^{+}-\mathrm{N} 、 \mathrm{NO}_{3}^{-}-\mathrm{N}$ 、 总无机氮及土壤温度和含水量的季节动态差异, 以及不同降雨处理下土壤累积氮矿化量和硝化量 之间的差异性。采用Pearson's相关分析检验土壤无 机氮含量、净氮矿化速率和净硝化速率、累积氮矿 化量和硝化量与土壤温度和含水量的相互关系。

\section{2 结果和分析}

\section{1 降雨处理和采样时间对土壤氮矿化、土壤温度 和含水量的影响}

重复测量方差分析(表1)表明，在2013年围封样 地，降雨处理对土壤 $\mathrm{NO}_{3}^{-}-\mathrm{N}$ 、无机氮和土壤含水量 具有显著影响 $(p<0.01)$, 除净氮矿化速率外, 采样 时间对土壤各项理化指标均有显著影响 $(p<0.01)$, 且降雨处理和采样时间二者之间的交互作用对土壤 $\mathrm{NH}_{4}^{+}-\mathrm{N}$ 和无机氮、土壤温度和含水量的影响显著 $(p<0.05)$; 在1999年围封样地, 降雨处理对土壤 $\mathrm{NH}_{4}^{+}$- $\mathrm{N}$ 和无机氮、土壤温度和含水量具有显著影 响 $(p<0.05)$, 采样时间对土壤各项理化指标均有显 著影响 $(p<0.01)$, 且降雨处理和采样时间二者的交 互作用对土壤 $\mathrm{NH}_{4}^{+}-\mathrm{N}$ 、净氮矿化速率和净硝化速率、 土壤含水量的影响显著 $(p<0.05)$ 。

\section{2 不同降雨强度和时间频次下土壤铵态氮、硝态 氮和无机氮的季节动态}

在2013年围封样地，从整体上看，各降雨处理 下，土壤 $\mathrm{NO}_{3}^{-}-\mathrm{N}$ 从6月初到 9 月初呈现出逐渐增加的

\begin{tabular}{|c|c|c|c|c|c|c|}
\hline \multirow[t]{2}{*}{ 土壤指标 Soil properties } & \multicolumn{3}{|c|}{ 2013年围封样地 Fenced site in 2013} & \multicolumn{3}{|c|}{ 1999年围封样地 Fenced site in 1999} \\
\hline & PT & ST & $\mathrm{PT} \times \mathrm{ST}$ & PT & ST & $\mathrm{PT} \times \mathrm{ST}$ \\
\hline 硝态氮 $\mathrm{NO}_{3}^{-}-\mathrm{N}\left(\mathrm{g} \cdot \mathrm{m}^{-2}\right)$ & $3.80^{* *}$ & $38.71^{* *}$ & $2.44^{\mathrm{ns}}$ & $1.19^{\mathrm{ns}}$ & $45.91^{* *}$ & $1.09^{\mathrm{ns}}$ \\
\hline 铵态氮 $\mathrm{NH}_{4}^{+}-\mathrm{N}\left(\mathrm{g} \cdot \mathrm{m}^{-2}\right)$ & $2.22^{\mathrm{ns}}$ & $112.13^{* *}$ & $1.92 *$ & $3.54^{* * *}$ & $63.46^{* *}$ & $2.18^{* *}$ \\
\hline 无机氮 Inorganic N $\left(\mathrm{g} \cdot \mathrm{m}^{-2}\right)$ & $3.68^{* *}$ & $113.56^{* *}$ & $1.82 *$ & $3.50 *$ & $95.29^{* *}$ & $1.54^{\mathrm{ns}}$ \\
\hline 净氮矿化速率 $R_{\min }\left(\mathrm{mg} \cdot \mathrm{m}^{-2} \cdot \mathrm{d}^{-1}\right)$ & $0.53^{\mathrm{ns}}$ & $0.25^{\mathrm{ns}}$ & $1.16^{\mathrm{ns}}$ & $0.82^{\mathrm{ns}}$ & $28.48^{* *}$ & $3.15^{* *}$ \\
\hline 净硝化速率 $R_{\mathrm{nit}}\left(\mathrm{mg} \cdot \mathrm{m}^{-2} \cdot \mathrm{d}^{-1}\right)$ & $0.90^{\mathrm{ns}}$ & $6.04^{* *}$ & $1.33^{\mathrm{ns}}$ & $1.05^{\mathrm{ns}}$ & $8.71^{* *}$ & $2.62 *$ \\
\hline 土壤温度 Soil temperature $\left({ }^{\circ} \mathrm{C}\right)$ & $1.85^{\mathrm{ns}}$ & $1275.85^{* *}$ & $3.11^{* *}$ & $6.80^{* *}$ & $1878.65^{* *}$ & $2.45^{\mathrm{ns}}$ \\
\hline 土壤含水量 Soil water content $(v / v, \%)$ & $11.81^{* *}$ & $288.70^{* *}$ & $2.70^{* *}$ & $5.21^{* *}$ & $195.01^{* *}$ & $3.10^{* *}$ \\
\hline
\end{tabular}
趋势, 并在9月初达到最大值, 但7月份和8月份的土 壤 $\mathrm{NO}_{3}^{-}-\mathrm{N}$ 含量并没有显著差异 $(p>0.05)$ (图1A)。此

表1 重复测量方差分析降雨处理 $(\mathrm{PT})$ 和采样时间 $(\mathrm{ST})$ 及其交互作用 $(\mathrm{PT} \times \mathrm{ST})$ 对土壤无机氮含量、净氮矿化速率和净硝化速率、土壤温度和含水量的影响 Table $1 F$ values of repeated measures analysis of variance for soil inorganic nitrogen $(\mathrm{N})$ concentrations, net $\mathrm{N}$ mineralization rate $\left(R_{\mathrm{min}}\right)$ and net nitrification rate $\left(R_{\text {nit }}\right)$, soil temperature and water content, using precipitation treatment $(\mathrm{PT})$, sampling time (ST), and their interactions $(\mathrm{PT} \times \mathrm{ST})$ as fixed-effects

${ }^{*}, p<0.05 ; * *, p<0.01 ; \mathrm{ns}, p>0.05$. 
外，在6月份和7月份，随着减雨时间频次减少(由连 续3年减雨至1年减雨处理), $\mathrm{NO}_{3}^{-}-\mathrm{N}$ 含量呈现出逐渐 下降的趋势，随着增雨时间频次增加(由1年增雨至 连续3年增雨处理), $\mathrm{NO}_{3}^{-}-\mathrm{N}$ 含量又随之增加。土壤 $\mathrm{NH}_{4}^{+}-\mathrm{N}$ 含量从6月份到7月份呈现非常显著的增加趋 势 $(p<0.01)$, 至8月份又略有下降, 然后到9月份又 维持较高值。在6月份, 随着减雨时间频次减少, 土 壤 $\mathrm{NH}_{4}^{+}$- $\mathrm{N}$ 含量逐渐降低, 而后随着增雨时间频次增
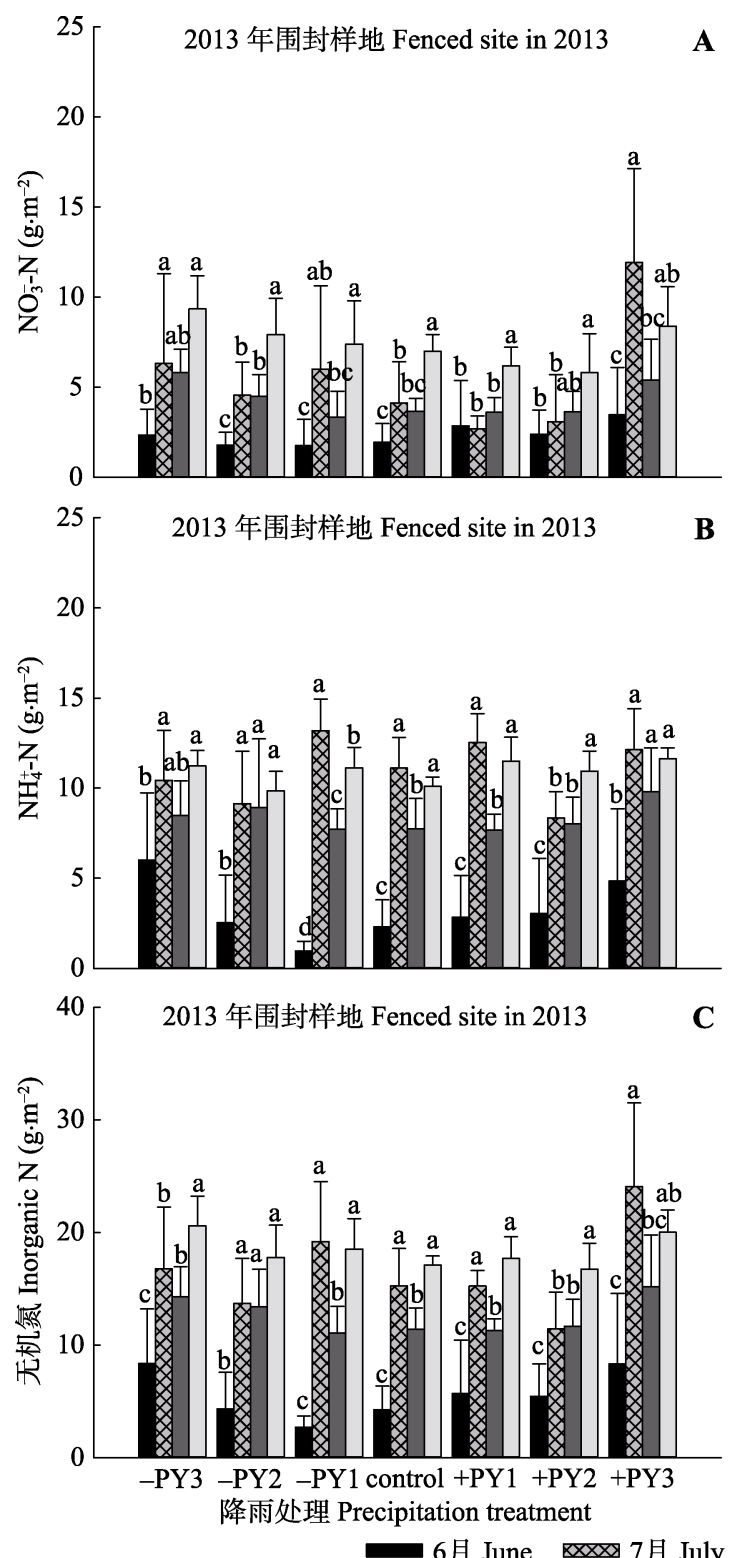

加, $\mathrm{NH}_{4}^{+}-\mathrm{N}$ 含量又随之增加，但是7、8和9月份 $\mathrm{NH}_{4}^{+}-\mathrm{N}$ 含量并没有表现出明显的增加或减少趋势 (图1B)。土壤无机氮含量从6月份到7月份呈显著增 加的趋势 $(p<0.05)$, 至8月份略有下降, 9月初又达 到最高值(图1C)。与对照相比(附录I), 仅7月份土壤 $\mathrm{NO}_{3}^{-}-\mathrm{N}$ 含量在连续增雨 3 年处理下 $(+\mathrm{PY} 3)$ 显著高于 对照 $(p<0.05)$, 而8月份在连续减雨3年处理下 (-PY3)显著高于对照 $(p<0.05)$ 。对于土壤 $\mathrm{NH}_{4}^{+}-\mathrm{N}$ 含
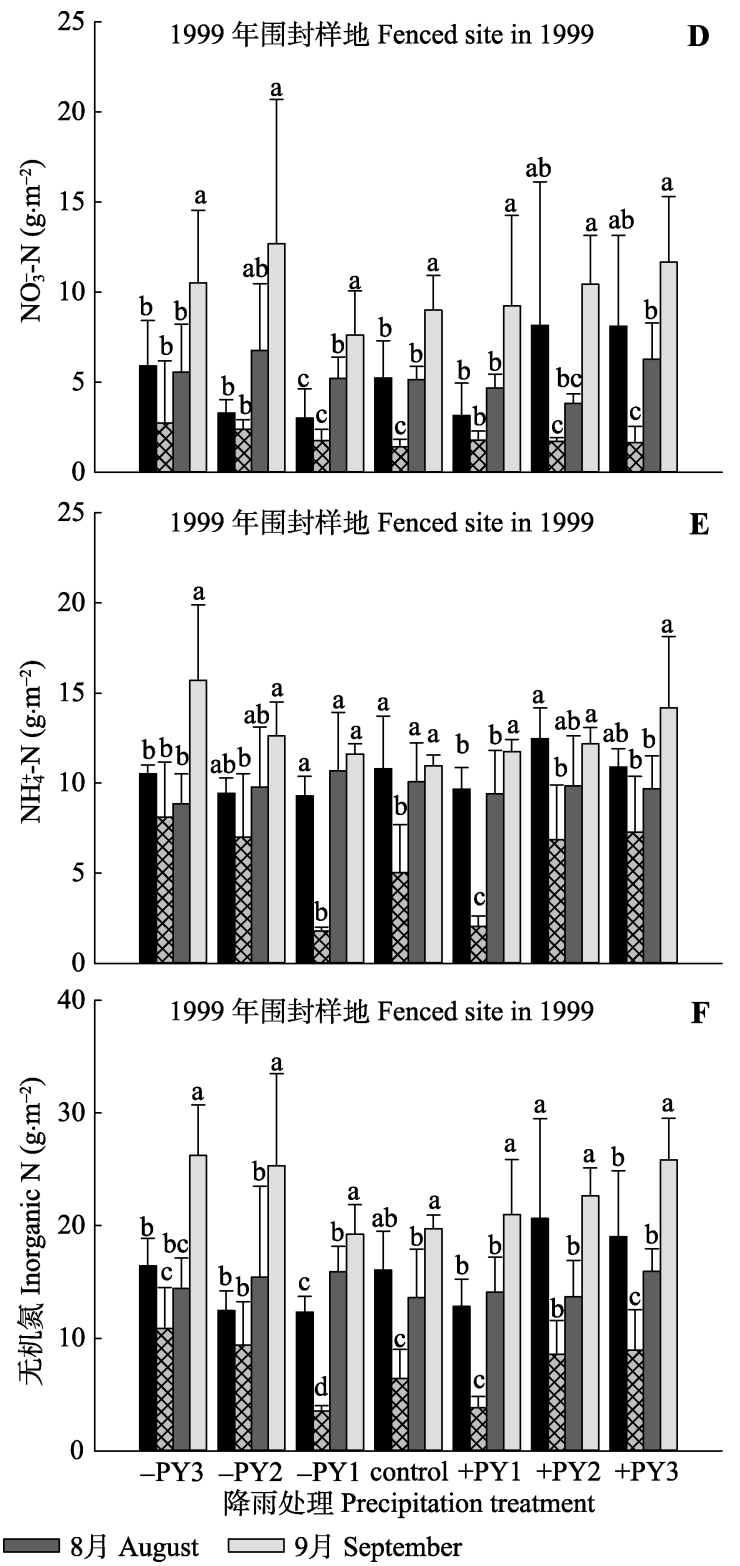

图1 土壤 $\mathrm{NH}_{4}^{+}-\mathrm{N} 、 \mathrm{NO}_{3}^{-}-\mathrm{N}$ 和无机氮含量在不同降雨强度和时间频次下的季节动态(平均值土标准误差, $n=5$ )。不同小写字母表 示同一降雨处理下不同月份之间的差异显著。降雨处理: control, 对照; -PY3, 连续减雨3年; - -PY2, 连续减雨 2 年后恢复1年; $-P Y 1$, 减雨1年后恢复1年; +PY1, 增雨1年后恢复1年; +PY2, 连续增雨2年后恢复1年; +PY3，连续增雨3年。

Fig. 1 Seasonal changes in soil $\mathrm{NH}_{4}^{+}-\mathrm{N}, \mathrm{NO}_{3}^{-}-\mathrm{N}$ and inorganic nitrogen $(\mathrm{N})$ concentrations at different precipitation intensity and temporal distribution treatments (mean $\pm S E, n=5$ ). Different lowercase letters indicate the significant differences among different months for a given precipitation treatment. Precipitation treatments: -PY3, decreased precipitation for three years; -PY2, decreased precipitation for two years and no treatment for one year; -PY1, decreased precipitation for one year and no treatment for one year; +PY1, increased precipitation for one year and no treatment for one year; +PY2, increased precipitation for two years and no treatment for one year; $+\mathrm{PY} 3$, increased precipitation for three years.

www.plant-ecology.com 
量, 在连续减雨3年处理下(-PY3)6月份显著高于对 照 $(p<0.05)$, 在连续增雨 2 年恢复一年处理下 $(+\mathrm{PY} 2) 7$ 月份显著低于对照 $(p<0.05)$, 而在增雨1年 恢复1年 $(+P Y 1)$ 和连续增雨3年处理下 $(+P Y 3)$ 9月份 显著高于对照 $(p<0.05)$ (附录I)。各处理下的土壤无 机氮含量与对照相比, 连续增雨3年处理下 $(+\mathrm{PY} 3)$ 7月份和8月份显著高于对照 $(p<0.05)$, 而9月份仅 在连续减雨 3 年处理中 $(-\mathrm{PY} 3)$ 显著高于对照 $(p<$ 0.05) (附录I)。

在1999年围封样地, 土壤 $\mathrm{NO}_{3}^{-}-\mathrm{N}$ 含量从6月初 到9月初呈现逐渐增加的趋势, 并在9月初达到最大 值(图1D)。土壤 $\mathrm{NH}_{4}^{+}-\mathrm{N}$ 含量从6月初到9月初, 也呈 现逐渐增加的趋势, 并在 9 月初达到最大值, 同时 7 月份的 $\mathrm{NH}_{4}^{+}-\mathrm{N}$ 含量也是最低值, 并呈现出随着减雨 时间频次的降低逐渐降低, 随着增雨时间频次的增 加, 其值在稳步增加(图1E)。整体而言, $\mathrm{NH}_{4}^{+}-\mathrm{N}$ 含量 在6、8和9月份并没有表现出显著性差异 $(p>0.05)$ 。

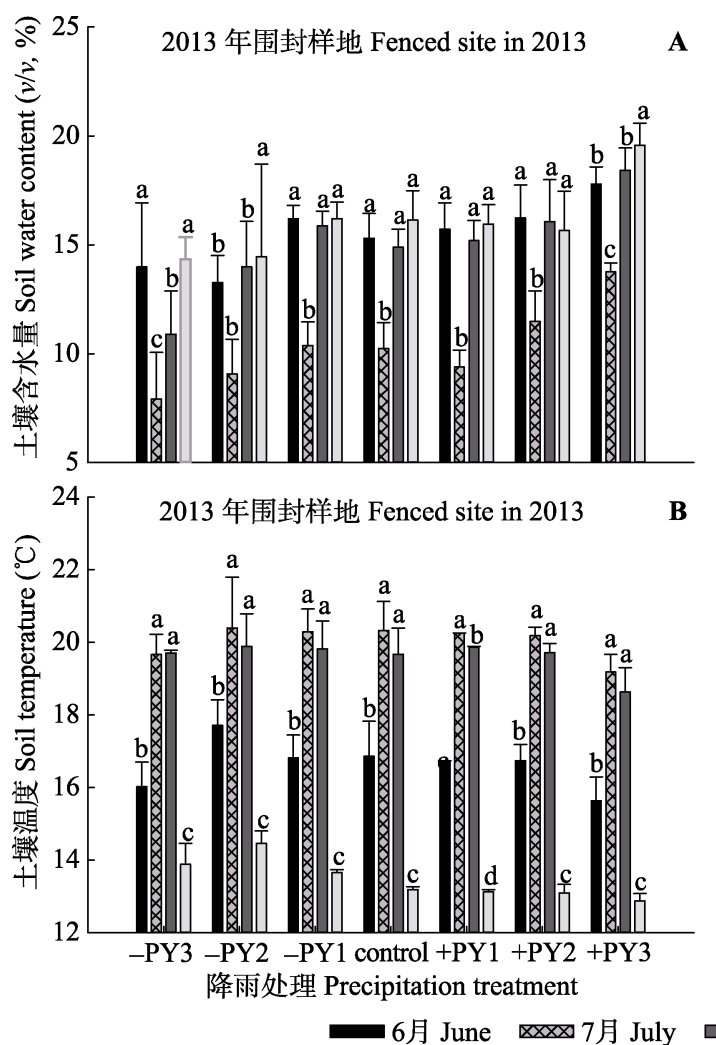

土壤无机氮含量从6月份到7月份呈显著降低的趋势 $(p<0.05)$, 至8月份又开始增加, 且在 9 月初达到最 大值(图1F)。与对照相比(附录II), 6-9月份, 各个处 理下土壤 $\mathrm{NO}_{3}^{-}-\mathrm{N}$ 含量并没有显著的变化 $(p>0.05)$, 而土壤 $\mathrm{NH}_{4}^{+}-\mathrm{N}$ 含量仅在 9 月份的连续减雨 3 年处理 $(-P Y 3)$ 和连续增雨 3 年处理下 $(+P Y 3)$ 显著高于对照 $(p<0.05)$ 。土壤无机氮含量在7月份连续减雨 3 年处 理下 $(-\mathrm{PY} 3)$ 和9月份连续减雨3年(-PY3)和连续增雨 3 年处理下 $(+P Y 3)$ 显著高于对照 $(p<0.05)$ (附录II)。

\section{3 不同降雨强度和时间频次下土壤温度和水分 的季节动态}

在2013年围封样地(图2A、2B)和1999年围封样 地(图2C、2D), 各降雨处理下, 从6月份至9月份, 土 壤含水量先下降后升高, 7 月份的土壤含水量最低, 8 月份次之，6月份和9月份的土壤含水量相对较高; 而土壤温度的变化趋势恰好相反, 从6月份至9月份, 土壤温度先升高后下降, 以7月份的土壤温度最高,

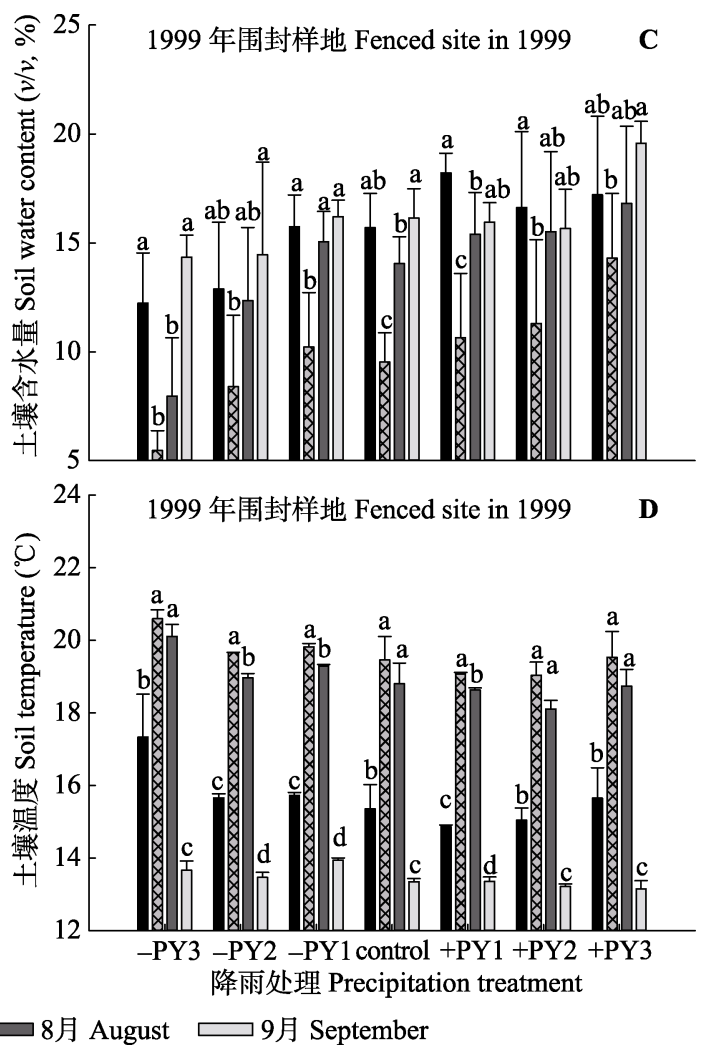

图2 土壤温度和含水量在不同降雨强度和时间频次下的季节动态(平均值沶准误差, $n=5$ )。不同小写字母表示同一降雨处 理下不同月份之间的差异显著。降雨处理: control, 对照; -PY3, 连续减雨3年; -PY2, 连续减雨2年后恢复1年; -PY1, 减雨1年 后恢复1年; +PY1，增雨1年后恢复1年; +PY2, 连续增雨2年后恢复1年; +PY3，连续增雨3年。

Fig. 2 Seasonal changes in soil temperature and water content at different precipitation intensity and temporal distribution treatments (mean $\pm S E, n=5$ ). Different lowercase letters indicate the significant differences among different months for a given precipitation treatment. Precipitation treatments: -PY3, decreased precipitation for three years; -PY2, decreased precipitation for two years and no treatment for one year; -PY1, decreased precipitation for one year and no treatment for one year; +PY1, increased precipitation for one year and no treatment for one year; +PY2, increased precipitation for two years and no treatment for one year; +PY3, increased precipitation for three years. 
8月份次之, 9月份的土壤温度最低。此外, 土壤含水 量随着降雨处理(减雨/增雨)的时间频次梯度(即降 雨总量增加)呈现出逐渐增加的趋势, 在连续增雨 3 年处理下 $(+P Y 3)$ 达到最高值。在2013年围封样地 $(r=-0.513, p<0.0001)$ 和1999年围封样地 $(r=$ $-0.548, p<0.0001)$, 土壤温度和含水量之间均呈现 出显著的负相关关系。
在2013年围封样地，增雨或减雨1年恢复1年处 理下，仅7月份土壤含水量在各处理间差异显著 $(p<$ $0.05)($ 图3A); 增雨或减雨2年恢复1年处理下，仅6月 份土壤含水量在各处理间差异显著 $(p<0.05)$, 连续 增雨 2 年处理下 $(+P Y 2)$ 土壤含水量高于连续减雨 2 年处理(-PY2)(图3B); 而连续增雨或减雨3年处理 下, 每个月各处理间土壤含水量均表现出显著的
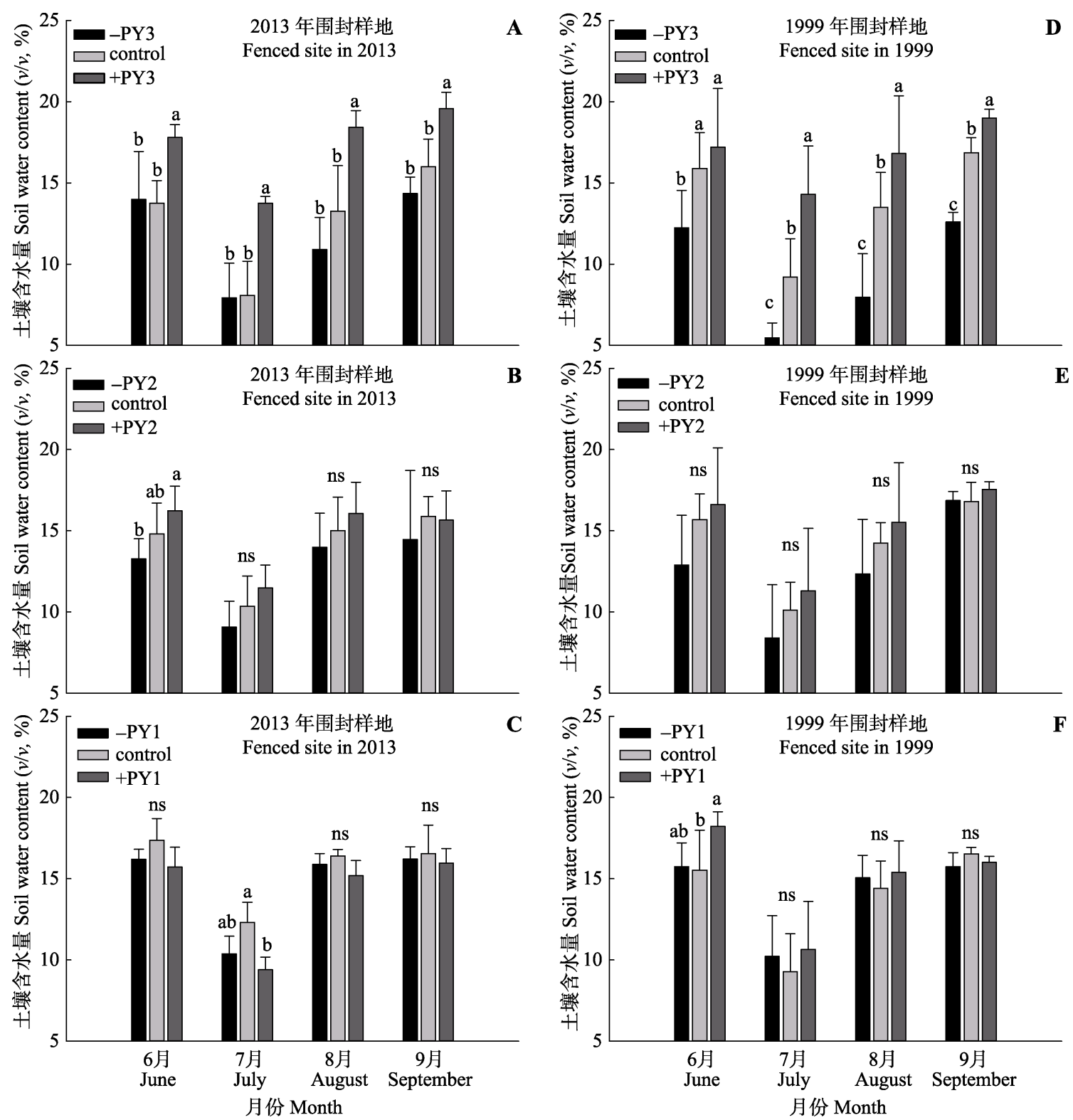

图3 降雨强度和时间频次对土壤含水量的影响(平均值土标准误差, $n=5$ )。不同小写字母表示同一月份不同降雨处理之间的 差异显著, ns表示同一月份不同降雨处理之间差异不显著。降雨处理: control, 对照; -PY3, 连续减雨3年; -PY2, 连续减雨2年 后恢复1年; $-\mathrm{PY} 1$, 减雨1年后恢复1年; $+\mathrm{PY} 1$, 增雨1年后恢复1年; +PY2, 连续增雨2年后恢复1年; +PY3, 连续增雨3年。

Fig. 3 Effects of precipitation intensity and temporal distribution on soil water content (mean $\pm S E, n=5$ ). Different lowercase letters indicate significant differences among precipitation treatments for a given month; ns indicates no significant difference among precipitation treatments for a given month. Precipitation treatments: -PY3, decreased precipitation for three years; -PY2, decreased precipitation for two years and no treatment for one year; -PY1, decreased precipitation for one year and no treatment for one year; $+\mathrm{PY} 1$, increased precipitation for one year and no treatment for one year; +PY2, increased precipitation for two years and no treatment for one year; +PY3, increased precipitation for three years. 
差异性 $(p<0.05)$, 且连续增雨 3 年处理下 $(+\mathrm{PY} 3)$ 土 壤含水量显著高于对照和连续减雨 3 年处理(-PY3) $(p<0.05)$, 但连续减雨3年处理 $(-\mathrm{PY} 3)$ 与对照无显 著差异 $(p>0.05$, 图3C)。在1999年围封样地, 增雨 或减雨 1 年恢复 1 年处理下, 仅6月份土壤含水量在 各处理间差异显著 $(p<0.05)$, 增雨1年恢复1年处理 下 $(+P Y 1)$ 土壤含水量高于对照 $(p<0.05)$ (图3D); 增 雨或减雨2年恢复1年处理下, 6-9月各处理间差异均 不显著 $(p>0.05)$ (图3E); 连续增雨或减雨3年处理 下, 每个月各处理间土壤含水量均表现出显著的差 异性, 且连续增雨3年处理下 $(+\mathrm{PY} 3)$ 土壤含水量显 著高于对照 $(p<0.05)$, 连续减雨3年处理 $(-\mathrm{PY} 3)$ 下 土壤含水量显著低于对照 $(p<0.05)$ (图3F)。总体而 言, 长时间连续性的增雨或减雨会显著影响土壤含 水量 $(p<0.05)$, 而短时间恢复处理下, 土壤含水量
并没有发生显著改变 $(p>0.05)$ 。

\section{4 土壤净氮矿化速率和净硝化速率、土壤累积氮 矿化量和硝化量}

在2013年围封样地, 6月份, 各处理下土壤净氮 矿化速率(图4A)和净硝化速率(图4B)与对照相比, 均没有显著差异 $(p>0.05)$, 但随着减雨时间频次的 降低, 土壤净氮矿化速率显著增加 $(p<0.05)$, 并在 减雨1年恢复1年处理(-PY1)下达到最大值; 7月份, 各处理下土壤净氮矿化速率和净硝化速率以负值居 多, 表明土壤发生氮固持现象, 且各处理的净氮矿 化速率与对照无显著差异, 增雨 1 年恢复 1 年处理 (+PY1)的土壤净硝化速率显著高于对照; 8月份, 连 续增雨3年处理(+PY3)的土壤净氮矿化速率显著低 于对照 $(p<0.05)$, 而各处理下净硝化速率与对照相 比，没有显著差异 $(p>0.05)$, 但在连续增雨2年恢复
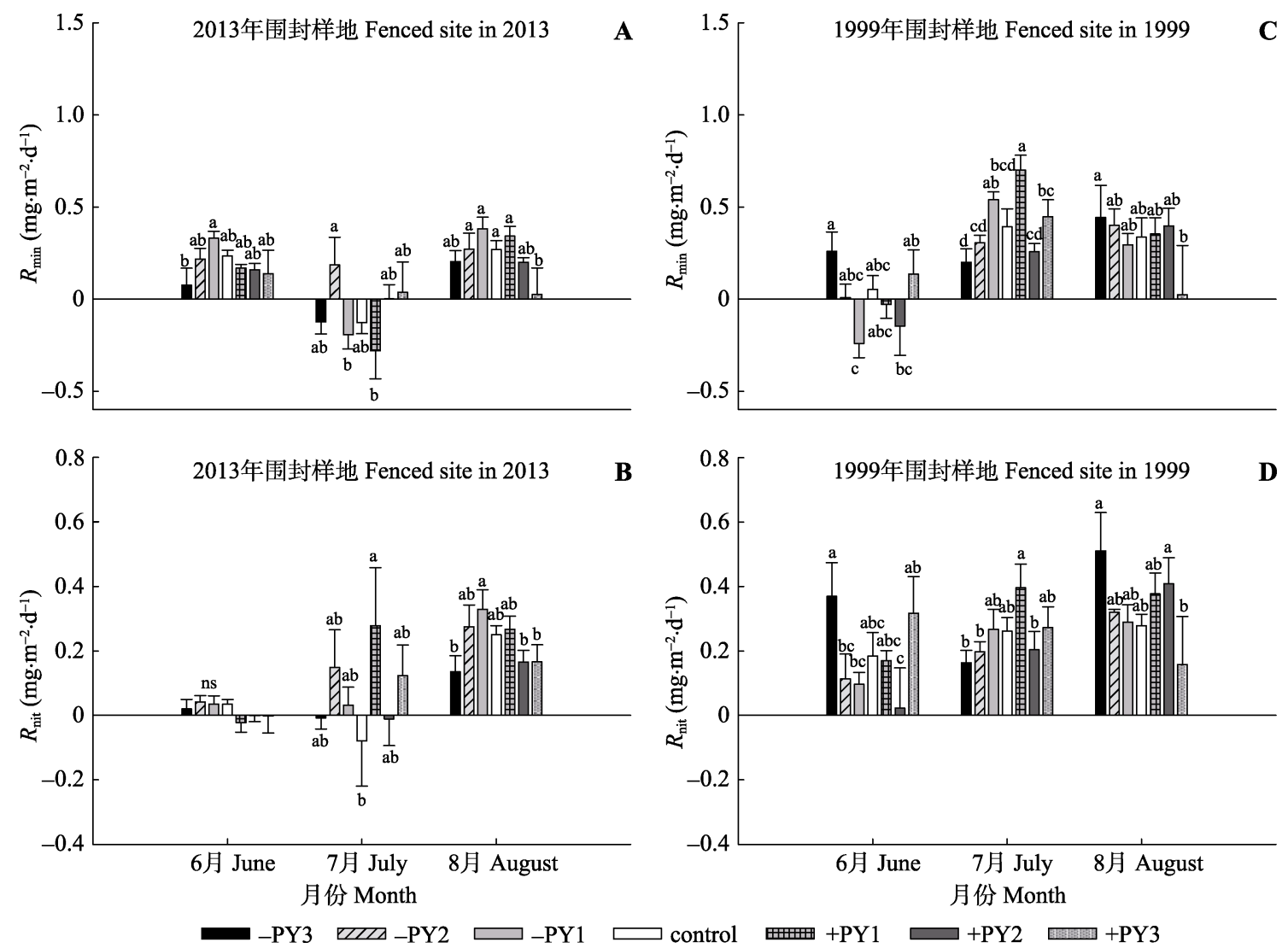

图4 降雨强度和时间频次对土壤净氮矿化速率 $\left(R_{\min }\right)$ 和净硝化速率 $\left(R_{\mathrm{nit}}\right)$ 的影响(平均值 \pm 标准误差, $\left.n=5\right)$ 。不同小写字母表示 同一月份不同降雨处理之间的差异显著, ns表示同一月份不同降雨处理之间差异不显著。降雨处理: control, 对照; -PY3, 连 续减雨3年; $-\mathrm{PY} 2$, 连续减雨2年后恢复1年; $-\mathrm{PY} 1$, 减雨1年后恢复1年; +PY1, 增雨1年后恢复1年; +PY2, 连续增雨 2 年后恢复 1年; + PY3, 连续增雨3年。

Fig. 4 Effects of precipitation intensity and temporal distribution on soil net $\mathrm{N}$ mineralization $\left(R_{\min }\right)$ and net nitrification rates $\left(R_{\text {nit }}\right)$ (mean $\pm S E, n=5$ ). Different lowercase letters indicate significant differences among precipitation treatments for a given month; ns indicates no significant difference among precipitation treatments for a given month. Precipitation treatments: -PY3, decreased precipitation for three years; -PY2, decreased precipitation for two years and no treatment for one year; -PY1, decreased precipitation for one year and no treatment for one year; +PY1, increased precipitation for one year and no treatment for one year; +PY2, increased precipitation for two years and no treatment for one year; +PY3, increased precipitation for three years. 
1 年 $(+P Y 2)$ 和连续增雨 3 年处理 $(+P Y 3)$ 的净硝化速 率为最低值。从总的趋势看, 随着减雨时间频次的 降低, 土壤净氮矿化速率和净硝化速率呈现出逐渐 增加的趋势, 而随着增雨时间频次的增加, 土壤净 氮矿化速率和净硝化速率呈现出逐渐减少的趋势 (图4A、4B)。

在1999年围封样地, 6月份, 各处理下, 土壤净 氮矿化速率较多呈负值或近乎0 (图4C), 表明土壤 发生氮固持现象, 净硝化速率随着减雨时间频次的 降低而降低(图4D); 7月份, 随着减雨时间频次的降 低, 土壤净氮矿化速率和净硝化速率显著增加 $(p<$ 0.05), 而随着增雨时间频次的增加, 土壤净氮矿化 速率和净硝化速率显著下降 $(p<0.05)$, 并在增雨 1 年恢复1年处理(+PY1)中, 土壤净氮矿化速率和净 硝化速率达到最大值。8月份, 随着减雨时间频次的 降低, 土壤净氮矿化速率和净硝化速率逐渐降低, 而随着增雨时间频次的增加, 土壤净氮矿化速率和 净硝化速率也呈降低趋势, 并在连续增雨3年处理 (+PY3)呈现最低值(图4C、4D)。
总体而言, 1999年围封样地的土壤净氮矿化速 率和净硝化速率高于2013年围封样地(图4C、4D)。 在2013年围封样地, 净氮矿化速率和净硝化速率 最高值出现在 8 月份, 以减雨 1 年恢复 1 年处理 (-PY1)的净氮矿化速率和净硝化速率最高(图4A、 4B); 而在1999年围封样地, 7月份的净氮矿化速率 最高, 8 月份的净硝化速率最高, 以增雨 1 年恢复 1 年处理 $(+P Y 1)$ 的净氮矿化速率和净硝化速率最高 (图4C、4D)。

在2013年围封样地和1999年围封样地, 土壤累 积氮矿化量和硝化量(6-8月之和)在各降雨处理下 均没有显著差异(图5)。比较而言, 1999年围封样地 的土壤累积氮矿化量(15.69-29.73 g. $\mathrm{m}^{-2}$ )(图5C)和 硝化量(19.28-28.26 g. $\left.\mathrm{m}^{-2}\right)$ (图5D)显著高于2013年 围封样地(4.28-21.31 $\mathrm{g} \cdot \mathrm{m}^{-2} ; 4.84-14.97 \mathrm{~g} \cdot \mathrm{m}^{-2}$ )(图 $5 A 、 5 B)(p<0.05)$, 且2013年围封样地的数值变异性 更高。

\section{5 土壤氮矿化与土壤温度和水分的关系}

在2013年围封样地, 土壤 $\mathrm{NH}_{4}^{+}-\mathrm{N} 、 \mathrm{NO}_{3}^{-}-\mathrm{N}$ 和净

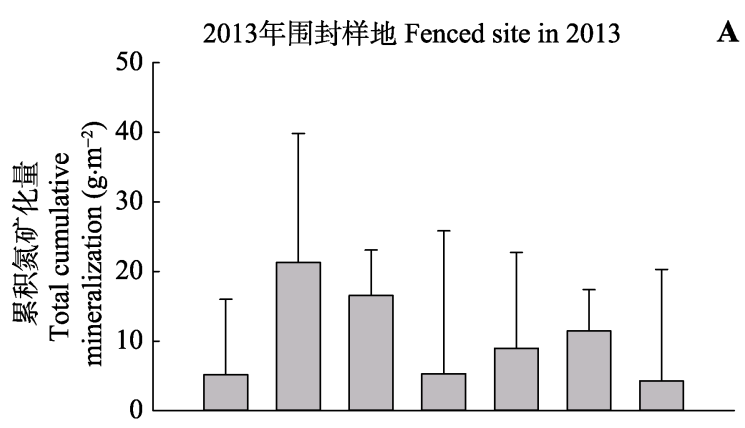

$\mathbf{A}$
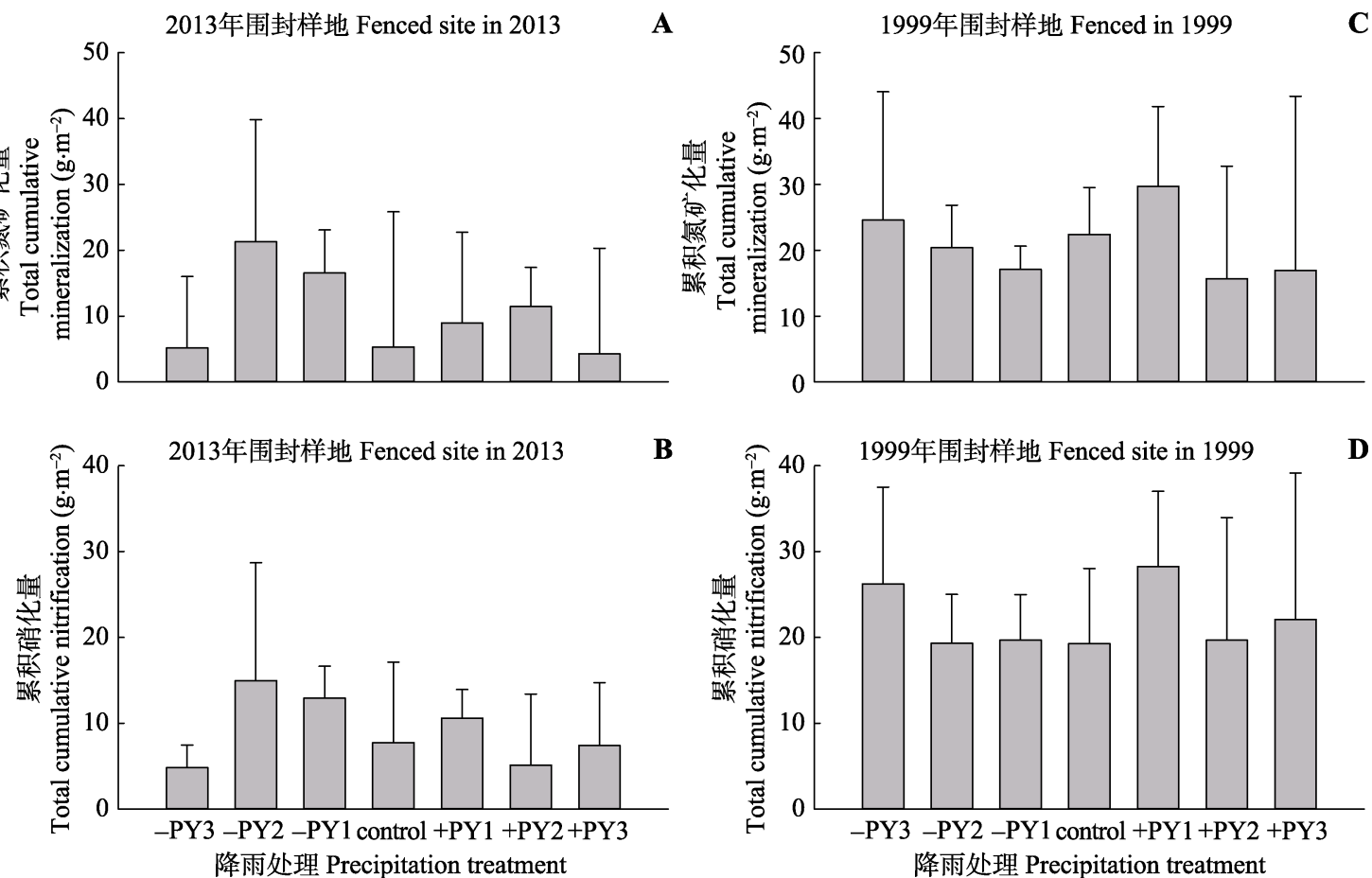

图5 降雨强度和时间频次对土壤累积氮矿化量和硝化量的影响(平均值土标准误差, $n=5$ )。各降雨处理间差异不显著。降雨 处理: control, 对照; -PY3, 连续减雨3年; -PY2, 连续减雨2年后恢复1年; -PY1, 减雨1年后恢复1年; +PY1, 增雨1年后恢复1 年; + PY2, 连续增雨2年后恢复1年; + PY3, 连续增雨3年。

Fig. 5 Effects of precipitation intensity and temporal distribution on total cumulative net nitrogen $(\mathrm{N})$ mineralization and nitrification (mean $\pm S E, n=5$ ). No significant difference among precipitation treatments. Precipitation treatments: -PY3, decreased precipitation for three years; -PY2, decreased precipitation for two years and no treatment for one year; -PY1, decreased precipitation for one year and no treatment for one year; +PY1, increased precipitation for one year and no treatment for one year; +PY2, increased precipitation for two years and no treatment for one year; +PY3, increased precipitation for three years. 
表2土壤无机氮、净氮矿化速率和净硝化速率、累积氮矿化量和硝化量与土壤温度和水分的相关关系

Table 2 Pearson correlation coefficients of soil inorganic nitrogen $(\mathrm{N})$, net $\mathrm{N}$ mineralization $\left(R_{\min }\right)$ and nitrification $\left(R_{\mathrm{nit}}\right)$ rates, cumulative net $\mathrm{N}$ mineralization $\left(C_{\min }\right)$ and nitrification $\left(C_{\text {nit }}\right)$ with soil temperature and water content

\begin{tabular}{|c|c|c|c|c|}
\hline \multirow[t]{2}{*}{ 土壤指标 Soil properties } & \multicolumn{2}{|c|}{ 2013年围封样地 Fenced site in 2013} & \multicolumn{2}{|c|}{ 1999年围封样地 Fenced site in 1999} \\
\hline & $\begin{array}{c}\text { 土壤温度 } \\
\text { Soil temperature }\left({ }^{\circ} \mathrm{C}\right)\end{array}$ & $\begin{array}{c}\text { 土壤含水量 } \\
\text { Soil water content (\%) }\end{array}$ & $\begin{array}{c}\text { 土壤温度 } \\
\text { Soil temperature }\left({ }^{\circ} \mathrm{C}\right)\end{array}$ & $\begin{array}{c}\text { 土壤含水量 } \\
\text { Soil water content (\%) }\end{array}$ \\
\hline 硝态氮 $\mathrm{NO}_{3}^{-}-\mathrm{N}\left(\mathrm{g} \cdot \mathrm{m}^{-2}\right)$ & $0.446^{* * * *}$ & $0.130^{\mathrm{ns}}$ & $0.125^{\mathrm{ns}}$ & $0.089^{\mathrm{ns}}$ \\
\hline 铵态氮 $\mathrm{NH}_{4}^{+}-\mathrm{N}\left(\mathrm{g} \cdot \mathrm{m}^{-2}\right)$ & $0.383^{* *}$ & $0.344^{* * * *}$ & $0.509^{* * *}$ & $-0.379^{* * *}$ \\
\hline 无机氮 Inorganic $\mathrm{N}\left(\mathrm{g} \cdot \mathrm{m}^{-2}\right)$ & $0.030^{\mathrm{ns}}$ & $0.347^{* * *}$ & $0.393^{* * *}$ & $-0.189^{\text {ns }}$ \\
\hline 净氮矿化速率 $R_{\min }\left(\mathrm{mg} \cdot \mathrm{m}^{-2} \cdot \mathrm{d}^{-1}\right)$ & $0.005^{\mathrm{ns}}$ & $0.317^{* * *}$ & $0.410^{* * *}$ & $-0.214^{*}$ \\
\hline 净硝化速率 $R_{\mathrm{nit}}\left(\mathrm{mg} \cdot \mathrm{m}^{-2} \cdot \mathrm{d}^{-1}\right)$ & $0.257^{*}$ & $0.064^{\mathrm{ns}}$ & $0.130^{\mathrm{ns}}$ & $0.027^{\mathrm{ns}}$ \\
\hline 累积氮矿化含量 $\mathrm{C}_{\min }\left(\mathrm{g} \cdot \mathrm{m}^{-2}\right)$ & $0.414^{\mathrm{ns}}$ & $0.071^{\mathrm{ns}}$ & $0.065^{\mathrm{ns}}$ & $0.455^{*}$ \\
\hline 累积硝化量 $C_{\text {nit }}\left(g \cdot m^{-2}\right)$ & $0.491^{\mathrm{ns}}$ & $0.018^{\mathrm{ns}}$ & $0.137^{\mathrm{ns}}$ & $0.539^{* *}$ \\
\hline
\end{tabular}

*, $p<0.05 ; * *, p<0.01 ; * * *, p<0.001 ; \mathrm{ns}, p>0.05$.

硝化速率与土壤温度均呈显著的正相关关系 $(p<$ 0.05), 土壤 $\mathrm{NH}_{4}^{+}-\mathrm{N}$ 、无机氮和净氮矿化速率与土壤 水分也呈显著的正相关关系 $(p<0.001)$; 在1999年 围封样地, 土壤 $\mathrm{NH}_{4}^{+}-\mathrm{N}$ 、无机氮和净氮矿化速率与 土壤温度均呈显著的正相关关系 $(p<0.001)$, 而土 壤 $\mathrm{NH}_{4}^{+}-\mathrm{N}$ 和净氮矿化速率与土壤水分呈显著的负相 关关系 $(p<0.05)$, 累积氮矿化量和硝化量与土壤水 分呈显著的正相关关系 $(p<0.05)$ (表2)。

因此, 总的来看, 土壤温度和水分对土壤 $\mathrm{NH}_{4}^{+}-\mathrm{N}$ 和净氮矿化速率的影响更大。在2013年围封 样地, 土壤无机氮和净氮矿化速率主要受土壤水分 的影响, 而土壤 $\mathrm{NO}_{3}^{-}-\mathrm{N}$ 和净硝化速率主要受土壤温 度的影响; 而在1999年围封样地, 土壤无机氮和净 氮矿化速率主要受土壤温度的影响, 土壤水分对净 氮矿化速率有一定的抑制作用，但对土壤累积氮矿 化量和硝化量有促进作用。

\section{3 讨论}

\section{1 降雨强度和时间频次对土壤氮矿化的影响}

本研究发现, 较长时间连续性的增雨或减雨 (如增雨或减雨3年)处理, 会降低土壤净氮矿化速率, 这与Zhou等(2012)和武丹丹等(2016)的研究结果较 为一致, 其原因可能是连续性的增/减雨显著地改 变了土壤含水量, 进而增加了土壤微生物的活性和 土壤酶的活性, 从而间接地提高了土壤氮矿化速率, 使得土壤氮矿化发生显著性变化(Knapp et al., 2001; 武丹丹等, 2016)。但是本研究结果与 Auyeung等 (2013)的研究结果(土壤含水量对土壤氮矿化产生负 作用)相反, 这可能是因为我们的试验结果仅仅涉 及生长季, 而未涉及全年的观测, 即时间尺度与其
有很大差异。同时我们也发现, 在两块样地中, 土壤 $\mathrm{NH}_{4}^{+}-\mathrm{N}$ 和 $\mathrm{NO}_{3}^{-}-\mathrm{N}$ 含量在不同季节(采样月份)的变化 规律也不尽相同, 这与刘杏认等(2007)在贝加尔针 茅草原和羊草草原的研究结果(土壤无机氮含量和 净氮矿化速率在不同的季节动态变化中存在着一定 的差异)有一定的相似之处。这些研究结果表明, 在 内蒙古半干旱草原, 水分作为主要的限制因子, 降雨 强度和时间频次会对土壤氮矿化产生重要影响。

本研究还发现, 长期的增雨或减雨处理会显著 影响土壤含水量和土壤温度, 进而显著地影响土壤 氮矿化作用, 其原因可能是长期的降雨处理改变了 土壤持水能力和微生物生物量, 进而对土壤净氮矿 化速率产生影响(Schimel et al., 1999; Luo et al., 2012); 而相对于较短时间频次的增雨或减雨处理, 土壤含水量和温度并没有发生显著改变, 以致对土 壤净氮矿化速率并没有产生较大的影响。我们也发 现, 不同的降雨强度和时间频次对土壤净氮矿化速 率的影响不尽相同, 如长时间连续增雨或减雨处理 下的土壤净氮矿化速率显著低于短时间恢复处理下 的土壤净氮矿化速率, 且在两块样地表现不同, 其 原因可能有以下几点：1)在较长时间减雨条件下, 土壤水分胁迫加剧, 抑制了土壤微生物活性, 进而 降低了土壤净氮矿化速率; 而较短时间的减雨处理, 经过 1 年恢复周期, 土壤含水量易恢复到正常范围, 使得微生物功能群组又恢复活性, 进而促进了土壤 净氮矿化速率(Schwinning \& Sala, 2004); 2)长时间 的增雨处理, 使得土壤含水量显著增加, 改变了土 壤的理化性质(如孔隙度下降), 降低了土壤中 $\mathrm{O}_{2}$ 的含量, 促进了微生物细胞的溶解作用, 抑制了土 壤微生物的活性, 从而降低了土壤净氮矿化速率 
(Lado Monserrat et al., 2014); 3)与1999年围封样地 相比, 2013年围封样地退化严重, 土壤持水性低, 水 分容易蒸发, 更易受到年际间降雨波动的影响。此 外, 两块样地的群落组成也不同, 2013年围封样地 主要以旱生从生禾草为优势种, 而1999年围封样地 主要以中旱生根茎禾草为优势种, 尤其是在生长季, 植物群落的不同可能也会对土壤氮矿化产生重要影 响(Jackson et al., 2008); 4)降雨处理在年际间的间断 性, 可能会引起土壤水分年际间的干湿交替现象, 进而对土壤氮矿化作用产生影响(Borken \& Matzner, 2009)。

我们还发现在2013年围封样地和1999年围封样 地，降雨强度和时间频次对土壤累积氮矿化量和硝 化量均没有产生显著的影响, 其原因可能是本试验 处理时间相对较短(2年), 降雨强度和时间频次虽然 对土壤氮矿化速率和无机氮含量产生一定的影响, 但不足以影响整个生长季的土壤累积氮矿化量和硝 化量。另外, 相对于地上植物群落, 土壤对外界的干 扰(如较短时间的降雨处理)具有较强的抗性和恢复 力, 以维持其稳定性(Moreira et al., 2016)。因此, 关 于降雨强度和时间频次对土壤氮矿化的影响, 还有 待于更长期的试验观测。

\section{2 不同围封年限样地土壤氮矿化响应的差异性 及其原因}

我们研究发现, 两块不同围封年限样地的土壤 氮矿化对降雨变化的响应具有明显的差异性, 且具 有不同的季节变化动态。例如, 在2013年围封样地, 从6月份至7月份, 土壤 $\mathrm{NH}_{4}^{+}-\mathrm{N}$ 和 $\mathrm{NO}_{3}^{-}-\mathrm{N}$ 呈显著增加 趋势, 而在1999年围封样地, 却呈明显的下降趋势, 从 8 月份至 9 月份, 两块样地的 $\mathrm{NH}_{4}^{+}-\mathrm{N}$ 和 $\mathrm{NO}_{3}^{-}-\mathrm{N}$ 均呈 现增加趋势。分析其原因可能是: 1) 2013年围封样 地, 6月份未发生土壤氮固持, 使得土壤 $\mathrm{NH}_{4}^{+}-\mathrm{N}$ 和 $\mathrm{NO}_{3}^{-}-\mathrm{N}$ 显著增加; 而1999年围封样地, 6月份开始氮 固持, 使得起始土壤 $\mathrm{NH}_{4}^{+}-\mathrm{N}$ 和 $\mathrm{NO}_{3}^{-}-\mathrm{N}$ 含量显著下 降。在8、9月份, 两块样地均未发生氮固持现象, 使 得8、9月份土壤 $\mathrm{NH}_{4}^{+}-\mathrm{N}$ 和 $\mathrm{NO}_{3}^{-}-\mathrm{N}$ 含量增加。2) 2013 年围封样地, 由于退化严重, 植被盖度较低, 这也 使得植物吸收土壤无机氮的量相对较少, 以致7月 份土壤 $\mathrm{NH}_{4}^{+}-\mathrm{N}$ 和 $\mathrm{NO}_{3}^{-}-\mathrm{N}$ 含量较高; 而1999年的围封 样地, 由于植物丰富度较高, 在生长季初期吸收土 壤 $\mathrm{NH}_{4}^{+}-\mathrm{N}$ 和 $\mathrm{NO}_{3}^{-}-\mathrm{N}$ 较多, 使得 7 月份土壤 $\mathrm{NH}_{4}^{+}-\mathrm{N}$ 和 $\mathrm{NO}_{3}^{-}-\mathrm{N}$ 含量下降, 然而在8月份, 土壤净氮矿化速率
增加, 植被生长状况稳定, 且趋向于衰老, 对土壤 $\mathrm{NH}_{4}^{+}-\mathrm{N}$ 和 $\mathrm{NO}_{3}^{-}-\mathrm{N}$ 的吸收较少, 以致9月份土壤无机 氮含量较高。总体而言, 与2013年围封样地相比, 1999年围封样地的土壤净氮矿化速率和净硝化速 率、土壤累积氮矿化量和硝化量更高, 表明长期自 然封育有利于养分储存和土壤质量恢复。

很多研究发现, 土壤含水量和土壤温度是影响 土壤无机氮库和氮矿化速率的两个主要因素(Wang et al., 2006; 李玉霖等, 2013), 尤其是在内蒙古半干 旱草原, 土壤水分可能是影响土壤氮矿化的首要限 制因子, 而土壤温度次之。如在2013年围封样地, 7 月份发生了土壤氮固持现象, 其原因可能是 7 月份 土壤含水量最低, 而土壤温度最高, 抑制了土壤氮 矿化速率。很多研究发现, 土壤水分是影响微生物 活性、加快土壤有机氮分解的重要因素之一(Cregger et al., 2014; Delgado Baquerizo et al., 2014), 而 温度又是提高土壤酶活性和土壤氧化作用的关键因 素(Prieto et al., 2011; Wang, 2014)。因此, 只有土壤 温度和土壤含水量处于一个相对比较适宜的条件下, 才会促进土壤氮矿化速率的增加(Chapin et al., 2011), 如果土壤含水量和温度高于或低于一定的 范围, 均会抑制土壤氮矿化速率(Wang et al., 2006)。 但是在1999年围封样地, 尽管7月份也是土壤水分 最低, 而土壤温度最高, 却没有发生氮固持现象, 其原因可能是其自然封育时间较长, 土壤对胁迫环 境的抗性和恢复力较强。此外, 我们研究也发现, 在 2013年和1999年围封样地, 土壤净氮矿化速率和净 硝化速率会随着增雨或减雨时间频次的增加而降低, 且其最高值均出现在减雨或增雨 1 年恢复 1 年处理 $( \pm P Y 1)$, 这些结果均表明, 降雨强度和时间频次过 大会对土壤氮矿化速率和净硝化速率产生抑制作用, 而适宜的土壤水分和温度条件更有利于氮矿化作用。

此外我们也发现, 相对于土壤 $\mathrm{NO}_{3}^{-}-\mathrm{N}$ 和净硝化 速率, 土壤温度和水分对土壤 $\mathrm{NH}_{4}^{+}-\mathrm{N}$ 和净氮矿化速 率的影响更大, 而且2013年围封样地和1999年围封 样地的土壤无机氮和净氮矿化速率的主要限制因子 也不同。在2013年围封样地, 土壤无机氮和净氮矿 化速率主要受土壤水分的影响, 而土壤 $\mathrm{NO}_{3}^{-}-\mathrm{N}$ 和净 硝化速率主要受土壤温度的影响; 而在1999年围封 样地, 土壤无机氮和净氮矿化速率主要受土壤温度 的影响, 土壤含水量则对土壤净氮矿化速率产生了 明显的负效应。其原因可能有以下两点: 首先, 由于 
2013年围封样地退化严重, 地表裸露程度较高, 使 得土壤更易受到光照的影响, 土壤温度增加, 促进 了土壤氧化作用 $\left(\mathrm{NH}_{4}^{+}\right.$离子转化为 $\mathrm{NO}_{3}^{-}$离子), 提高 了土壤净硝化速率(D’Odorico et al., 2003; 张亚峰 等, 2013; 刘任涛等, 2015), 另外, 由于土壤容重较 大导致保水性能低, 更加容易散失水分(Weber \& Gokhale, 2011), 因而, 土壤净氮矿化速率受水分的 限制作用更大。其次, 1999年围封样地由于围封时间 较长, 地上初级生产力较高, 群落趋于成熟和稳定 (Bai et al., 2004), 以致土壤保水性能较强, 有机氮 含量也较多(Shan et al., 2011), 而增雨处理更易使 土壤含水量高于某一阈值, 从而对土壤氮矿化产生 抑制作用。刘任涛等(2015)通过不同的增雨梯度试 验研究发现, 增加40\%-80\%降雨处理, 土壤温度均 有不同程度的增加, 其原因可能是增雨促进了土壤 最高温度位相的提前, 直接影响了土壤的热力学性 质, 加速了土壤的热传导过程(刘吉平等, 2005), 该 研究也可以很好地支持本研究结果。

\section{4 小结}

本研究以内蒙古典型草原不同围封年限样地为 研究对象, 通过设置降雨控制实验, 研究了不同的 降雨强度和时间频次对草原生态系统土壤氮矿化的 影响, 主要结果发现: 1)较高的降雨强度和时间频 次对土壤净氮矿化速率和净硝化速率会产生抑制作 用, 而适宜的土壤水分和温度条件更有利于土壤氮 矿化作用。2)长期的增雨或减雨处理会显著影响土 壤含水量和土壤温度, 进而显著地影响土壤氮矿化 作用; 相对于土壤硝态氮和净硝化速率, 土壤水分 和温度对土壤铵态氮和净氮矿化速率的影响更大。 3)两块不同围封年限样地的土壤氮矿化对降雨变化 的响应具有明显的差异性, 且主要影响因子不同。 短期围封样地(2013年围封)土壤氮矿化主要受土壤 含水量的影响, 而长期围封样地(1999年围封)主要 受土壤温度的影响, 长期围封样地的土壤净氮矿化 速率和净硝化速率、土壤累积氮矿化量和硝化量较 高, 表明长期的自然封育有利于养分储存和土壤质 量恢复。

基金项目 国家重点研发计划(2016YFC0500801和 2016YFC0500804)和国家自然科学基金(41671046)。

致谢 感谢中国科学院内蒙古草原生态系统定位研
究站的所有老师和工作人员, 以及江西师范大学和 唐山师范学院的志愿者在野外试验中给予的帮助。

\section{参考文献}

Amundson R, Austin AT, Schuur EA, Yoo K, Matzek V, Kendall C, Uebersax A, Brenner D, Baisden WT (2003). Global patterns of the isotopic composition of soil and plant nitrogen. Global Biogeochemical Cycles, 17, 1031, doi: 10.1029/2002GB001903.

Andersson P, Berggren D, Nilsson I (2002). Indices for nitrogen status and nitrate leaching from Norway spruce (Picea abies (L.) Karst.) stands in Sweden. Forest Ecology and Management, 157, 39-53.

Aranibar JN, Otter L, Macko SA, Feral CW, Epstein HE, Dowty PR, Eckardt F, Shugart HH, Swap RJ (2004). Nitrogen cycling in the soil-plant system along a precipitation gradient in the Kalahari sands. Global Chang Biology, 10, 359-373.

Auyeung DSN, Suseela V, Dukes JS (2013). Warming and drought reduce temperature sensitivity of nitrogen transformations. Global Change Biology, 19, 662-676.

Bai YF, Han XG, Wu JG, Chen ZZ, Li LH (2004). Ecosystem stability and compensatory effects in the Inner Mongolia grassland. Nature, 431, 181-184.

Borken W, Matzner E (2009). Reappraisal of drying and wetting effects on $\mathrm{C}$ and $\mathrm{N}$ mineralization and fluxes in soils. Global Change Biology, 15, 808-824.

Burke IC, Lauenroth WK, Vinton MA, Hook PB, Kelly RH, Epstein HE, Aguiar MR, Robles MD, Aguilera MO, Murphy KL (1998). Plant-soil interactions in temperate grasslands. Biogeochemistry, 42, 121-143.

Chapin FS III, Matson PA, Vitousek PM (2011). Principles of Terrestrial Ecosystem Ecology. 2nd edn. Springer, New York,

Chen QH, Feng Y, Zhang YP, Zhang QC, Shamsi IH, Zhang YS, Lin XY (2012). Short-term responses of nitrogen mineralization and microbial community to water content regimes in greenhouse vegetable soils. Pedosphere, 22, 263-272.

Cregger MA, Mcdowell NG, Pangle RE, Pockman WT, Classen AT, Niu SL (2014). The impact of precipitation change on nitrogen cycling in a semi-arid ecosystem. Functional Ecology, 28, 1534-1544.

D’odorico P, Laio F, Porporato A, Rodriguez-Iturbe I (2003). Hydrologic controls on soil carbon and nitrogen cycles. II. A case study. Advances in Water Resources, 26, 45-58.

Delgado Baquerizo M, Maestre FT, Escolar C, Gallardo A, Ochaoa V, Gozalo B, Prado A, Wardle D (2014). Direct and indirect impacts of climate change on microbial and biocrust communities alter the resistance of the $\mathrm{N}$ cycle in a semiarid grassland. Journal of Ecology, 102, 1592-1605. 
Department of Animal Husbandry and Veterinary, General Station of Animal Husbandry and Veterinary of Ministry of Agriculture of China (1996). Rangeland Resources of China. China Science and Technology Press, Beijing. (in Chinese) [中华人民共和国农业部畜牧兽医司，全国畜 牧兽医总站 (1996). 中国草地资源. 中国科学技术出版 社, 北京.]

Frank DA, Groffman PM, Evans RD, Tracy BF (2000). Ungulate stimulation of nitrogen cycling and retention in Yellowstone Park grasslands. Oecologia, 123, 116-121.

Goodale CL, Aber JD (2001). The long-term effects of land-use history on nitrogen cycling in northern hardwood forests. Ecological Applications, 11, 253-267.

Hu R, Wang XP, Pan YX, Zhang YF, Zhang H (2014). The response mechanisms of soil $\mathrm{N}$ mineralization under biological soil crusts to temperature and water content in temperate desert regions. European Journal of Soil Biology, 62, 66-73.

IPCC (Intergovernmental Panel on Climate Change) (2014). Contribution of working group III to the fifth assessment report of the intergovernmental panel on climate change. In: Edenhofer O, Pichsmadruga R, Sokana Y eds. Climate Change 2014: Mitigation of Climate Change. Cambridge University Press, Cambridge, UK.

Jackson LE, Burger M, Cavagnaro TR (2008). Roots, nitrogen transformations, and ecosystem services. Annual Review of Plant Biology, 59, 341-363.

Jiang S, Li B, Wang YF (1988). Methology of Grassland Ecology. Agricultural Press, Beijing. 32-38. (in Chinese) [姜 恕, 李博, 王义凤 (1988). 草地生态研究方法. 农业出 版社, 北京. 32-38.]

Knapp AK, Briggs JM, Koelliker JK (2001). Frequency and extent of water limitation to primary production in a mesic temperate grassland. Ecosystems, 4, 19-28.

Knapp AK, Smith MD (2001). Variation among biomes in temporal dynamics of aboveground primary production. Science, 291, 481-484.

Lado Monserrat L, Lull C, Bautista I, Lidón A, Herrera R (2014). Soil water content increment as a controlling variable of the "Birch effect". Interactions with the pre-wetting soil water content and litter addition. Plant and Soil, 379, 21-34.

Li YL, Chen J, Cui D, Wang XY, Zhao XY (2013). Effects of warming on Soil nitrogen mineralization under different soil water content conditions in the Horqin sandy grassland. Journal of Desert Research, 33, 1775-1781. (in Chinese with English abstract) [李玉霖, 陈静, 崔夺, 王 新源, 赵学勇 (2013). 不同含水量条件下模拟增温对科 尔沁沙质草地土壤氮矿化的影响. 中国沙漠, 33, 17751781.]

Liao X, Inglett PW, Inglett KS (2016). Seasonal patterns of nitrogen cycling in subtropical short-hydroperiod wet- lands: Effects of precipitation and restoration. Science of the Total Environment, 556, 136-145.

Liu JP, Yang Q, Lü XG (2005). Studies on the soil temperature gradient in annular wetlands in the Sanjing Plain, China. Wetland Science, 3, 42-47. (in Chinese with English abstract) [刘吉平, 杨青, 吕宪国 (2005). 三江平原环型湿 地土壤温度梯度的研究. 湿地科学, 3, 42-47.]

Liu RT, Zhu F, Chen L (2015). Effects of simulated summer rainfall increases on soil temperature in sandy grassland. Chinese Journal of Soil Science, 2, 348-354. (in Chinese with English abstract) [刘任涛, 朱凡, 陈林 (2015). 降 雨增加对沙质草地土壤温度的影响. 土壤通报, 2, 348354.]

Liu XR, Dong YS, Qi YC, Domroes M (2007). Soil net nitrogen mineralization in the typical temperate grassland. Environmental Science, 28, 633-639. (in Chinese with English abstract) [刘杏认, 董云社, 齐玉春, Domroes M (2007). 温带典型草地土壤净氮矿化作用研究. 环境科 学, 28, 633-639.]

Luo CY, Wang S, Zhao L, Xu SX, Xu BY, Zhang ZH, Yao BQ, Zhao XQ (2012). Effects of land use and management on ecosystem respiration in alpine meadow on the Tibetan Plateau. Soil \& Tillage Research, 124, 161-169.

Moreira WH, Tormena CA, Karlen DL, Da Silva P, Keller T, Betioli E (2016). Seasonal changes in soil physical properties under long-term no-tillage. Soil and Tillage Research, 160, 53-64.

Prieto LH, Bertiller MB, Carrera AL, Olivera NL (2011). Soil enzyme and microbial activities in a grazing ecosystem of Patagonian Monte, Argentina. Geoderma, 162, 281-287.

Schimel JP, Gulledge JM, Clein Curley JS, Lindstrom JE, Braddock JF (1999). Water content effects on microbial activity and community structure in decomposing birch litter in the Alaskan taiga. Soil Biology \& Biochemistry, 31, 831-838.

Schwinning S, Sala OE (2004). Hierarchy of responses to resource pulses in arid and semi-arid ecosystems. Oecologia, 141, 211-220.

Shan YM, Chen DM, Guan XX, Zheng SX, Chen HJ, Wang MJ, Bai YF (2011). Seasonally dependent impacts of grazing on soil nitrogen mineralization and linkages to ecosystem functioning in Inner Mongolia grassland. Soil Biology \& Biochemistry, 43, 1943-1954.

Tang SM, Qi ZP (1997). The relationship between soil water contents and nitrogen mineralization. Chinese Journal of Tropical Agriculture, 4, 54-60. (in Chinese with English abstract) [唐树梅, 漆智平 (1997). 土壤水含量与氮矿 化的关系. 热带农业科学, 4, 54-60.]

Templer PH, Groffman PM, Flecker AS, Power AG (2005). Land use change and soil nutrient transformations in the Los Haitises region of the Dominican Republic. Soil Biology \& Biochemistry, 37, 215-225.

www.plant-ecology.com 
Tong XJ, Tao B, Cao MK (2005). The responses of soil respiration and nitrogenmineralization to global warming in terrestrial ecosystems. Progress in Geography, 24, 84-96. (in Chinese with English abstract) [同小娟, 陶波, 曹明奎 (2005). 陆地生态系统土壤呼吸、氮矿化对气候变暖的 响应. 地理科学进展, 24, 84-96.]

Tracy BF, Frank DA (1998). Herbivore influence on soil microbial biomass and nitrogen mineralization in a northern grassland ecosystem: Yellowstone National Park. Oecologia, 114, 556-562.

Wang CH, Wan SQ, Xing XR, Zhang L, Han XG (2006). Temperature and soil water content interactively affected soil net $\mathrm{N}$ mineralization in temperate grassland in Northern China. Soil Biology \& Biochemistry, 38, 1101-1110.

Wang R (2014). Coupled response of soil carbon and nitrogen pools and enzyme activities to nitrogen and water addition in a semi-arid grassland of Inner Mongolia. Plant and Soil, 381, 323-336.

Weber KT, Gokhale BS (2011). Effect of grazing on soil-water content in semiarid rangelands of southeast Idaho. Journal of Arid Environments, 75, 464-470.

Weltzin JF, Loik ME, Schwinning S, Williams DG, Fay PA, Haddad BM, Hsrte John, Huxman TE, Knapp AK, Lin GH, Pockman WT, Shaw MR, Small EE, Smith MD, Smith SD, Tissue DT, Zak JC (2009). Assessing the response of terrestrial ecosystems to potential changes in precipitation. Bioscience, 53, 941-952.

Wu DD, Jing X, Lin L, Yang XY, Zhang ZH, He JS (2016). Responses of soil inorganic nitrogen to warming and altered precipitation in an alpine meadow on the Qinghai-Tibetan Plateau. Acta Scientiarum Naturalium Universitatis Pekinensis, 52, 959-966. (in Chinese with English abstract) [武丹丹, 井新, 林笠, 杨新宇, 张振华, 贺金
生 (2016). 青藏高原高寒草甸土壤无机氮对增温和降 水改变的响应. 北京大学学报 (自然科学版), 52, 959-966.]

Wu JG, Han M, Chang W, Ai L, Chang XX (2007). The mineralization of soil nitrogen and its influenced factors under alpine meadows in Qilian Mountains. Acta Prataculturae Sinica, 16, 39-46. (in Chinese with English abstract) [ 吴建 国, 韩梅, 茩伟, 艾丽, 常学向 (2007). 祁连山中部高 寒草甸土壤氮矿化及其影响因素研究. 草业学报, 16, 39-46.]

Yahdjian L, Sala OE (2002). A rainout shelter design for intercepting different amounts of rainfall. Oecologia, 133, 95101.

Yin YT, Hou XY, Yun XJ (2011). Advances in the climate change influencing grassland ecosystems in Inner Mongolia. Pratacultural Science, 28, 1132-1139. (in Chinese with English abstract) [尹燕亭, 侯向阳, 运向军 (2011). 气候变化对内蒙古草原生态系统影响的研究进展. 草 业科学, 28, 1132-1139.]

Zhang YF, Wang XP, Hu R, Pan YX (2013). Effects of shrubs and precipitation on spatial-temporal variation of soil temperature at the microhabitats induced by desert shrubs. Journal of Desert Research, 33, 536-542. (in Chinese with English abstract) [张亚峰, 王新平, 虎瑞, 潘颜霞 (2013). 荒漠灌从微生境土壤温度的时空变异特征一一 灌从与降水的影响. 中国沙漠, 33, 536-542.]

Zhou XQ, Chen CR, Wang YF, Xu ZH, Han HY, Li LH, Wan SQ (2012). Effects of warming and increased precipitation on soil carbon mineralization in an Inner Mongolian grassland after 6 years of treatments. Biology and Fertility of Soils, 48, 859-866.

特邀编委: 方运霆 责任编辑: 王 藏

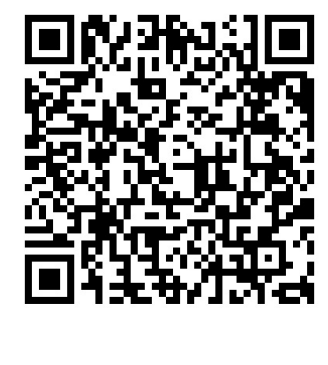



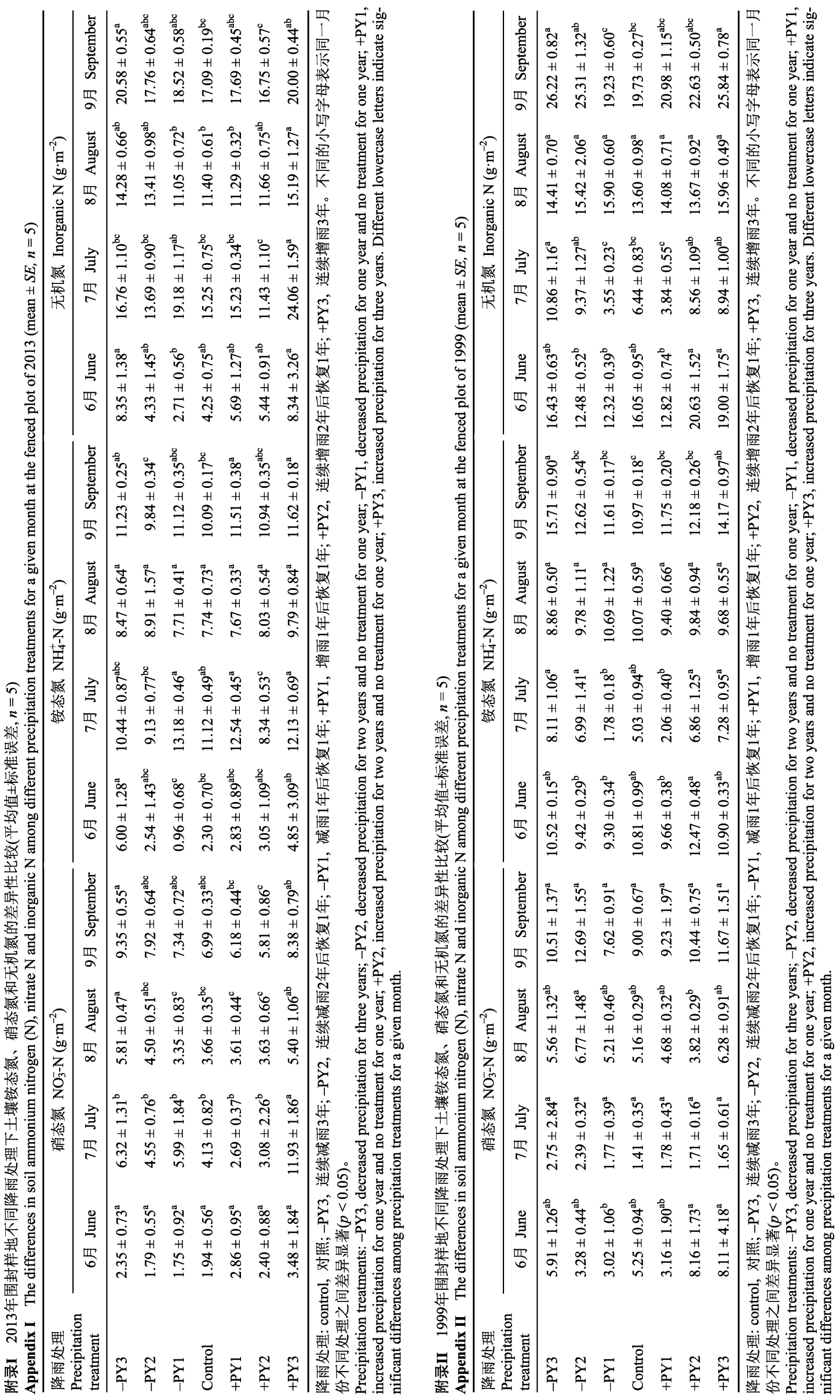

www.plant-ecology.com 